\title{
Subjective Cognitive Complaints and Permanent Work Disability: A Prospective Cohort Study of 7,161 Employees in Primarily Knowledge-intensive Occupations with an up to Eight-Year Follow-up
}

\author{
Minna Pihlajamäki ( $\nabla$ minna.pihlajamaki@live.com ) \\ Tampereen Yliopisto https://orcid.org/0000-0003-1491-8771 \\ Heikki Arola
}

Terveystalo

Heini Ahveninen

Terveystalo

Jyrki Ollikainen

Tampereen Yliopisto

Mikko Korhonen

Tampereen Yliopisto

Tapio Nummi

Tampereen Yliopisto

Jukka Uitti

Tampereen Yliopisto

Simo Taimela

Helsingin Yliopisto

Research article

Keywords: Occupational health care, Self-reported data, Disability retirement, Register data, Subjective cognitive complaints, Fine-Gray model, Cumulative incidence function

Posted Date: January 16th, 2020

DOl: https://doi.org/10.21203/rs.2.21053/v1

License: (1) This work is licensed under a Creative Commons Attribution 4.0 International License.

Read Full License 
Subjective Cognitive Complaints and Permanent Work Disability: A Prospective Cohort Study of

7,161 Employees in Primarily Knowledge-intensive Occupations with an up to Eight-Year Followup

Minna Pihlajamäki, MD ${ }^{1}$; Heikki Arola, MD, PhD ${ }^{2}$; Heini Ahveninen, MD ${ }^{2}$; Jyrki Ollikainen, MSc ${ }^{3}$;

Mikko Korhonen, $\mathrm{MSc}^{3}$; Tapio Nummi, $\mathrm{PhD}^{3}$; Jukka Uitti, MD, $\mathrm{PhD}^{1,4,5}$; Simo Taimela, MD, PhD 6,7

1) Faculty of Medicine and Health Technology, Tampere University, Finland

2) Terveystalo, Jaakonkatu 3b, 00100 Helsinki, Finland

3) Faculty of Information Technology and Communication Sciences, Tampere University, Finland

4) Clinic of Occupational Medicine, Tampere University Hospital, Finland

5) Finnish Institute of Occupational Health, Tampere, Finland

6) Clinicum, Department of Orthopedics and Traumatology, University of Helsinki, Finland

7) Evalua International, PO Box 35, FIN-02661 Espoo, Finland

Corresponding Author:

Minna Pihlajamäki, MD

tel. +358407568308

email: minna.pihlajamaki@tuni.fi

Mail address: Kalervonsola 1A1, 60120 Seinäjoki, Europe - Finland

Running Head: Subjective Cognitive Complaints and Disability Benefits 


\section{Abstract}

Background: Work disability (WD) is a medico-legal concept that refers to disability benefits (DB) granted due to diseases. We assessed whether subjective cognitive complaints (SCC) - presenting as self-rated difficulties of concentration, memory, clear thinking and decision making - predict permanent WD in knowledge-intensive occupations.

Methods: We combined the SCC questionnaire results with reliable registry data on the DBs of 7,161 professional/managerial employees ( $46 \%$ females). We excluded employees who were on longterm sickness absence (SA) or had received a DB at baseline. The exposure variable was the presence of SCC. Age and SA before the questionnaire as a proxy measure of general health were treated as confounders and the analyses were conducted by gender. The outcome variable was a granted DB. The cumulative incidence function illustrates the difference between SCC categories, and the FineGray model estimates the predictors of WD during the eight-year follow-up.

Results: The most common primary reasons for permanent WD were mental (36\%) and musculoskeletal (20\%) disorders. SCC predicted DB in both genders when controlling for age and prior SA. Hazard ratios were 2.9 with a 95\% confidence interval 1.4-6.0 for the females and 3.7 (1.87.9) for the males. After eight years, $3.1 \%$ of the females and $2.8 \%$ of the males in the abnormal SCC category had received a DB, while the respective figures in the reference category were $1.9 \%$ and $1.0 \%$.

Conclusion: Subjective cognitive complaints predict permanent WD in knowledge-intensive occupations among professional/managerial employees. This finding has implications for supporting work ability among employees with cognitively demanding tasks.

Keywords: Occupational health care; Self-reported data; Disability retirement; Register data; Subjective cognitive complaints, Fine-Gray model; Cumulative incidence function 


\section{Background}

Permanent work disability (WD) is one of the greatest societal challenges for OECD countries (1). The share of older people in the workforce is constantly growing (2), life expectancies are rising, and the retirement age is increasing (3). Rapid changes are taking place in our knowledge-based working-life (4), which may create a scattered psychosocial work environment that overloads cognitive capacity due to multiple communication and information channels, for example.

WD is a medico-legal concept (5), which in Finland is defined as having been granted a work disability benefit (DB). In Finland, 144,600 individuals among the working-age population of 2.5 million (5.7\%) have retired prematurely due to permanent WD (6), and there were 19,900 new disability benefit (DB) recipients in 2018, of which $31 \%$ were granted due to behavioural and mental disorders (7). The benefits programme of the Social Insurance Institution of Finland (Kela) provides coverage for lost income due to a medically certified sickness for up to one year. Thereafter, the DB scheme, which is operated by pension insurance companies, covers lost income for those eligible. Work ability is assessed on the basis of the employee's remaining ability to earn an income from work that can reasonably be expected on the basis of his/her education, previous work history, age, housing conditions, and other social factors. A DB is granted if, based on the attending physician's statement, the employee's ability to work is permanently reduced and the expert panel agrees that the decrease in functional capacity and work ability is due to illness or injury. Thus, a granted DB serves as a proxy for permanent WD in the present study.

Work ability and disability are complex and multifactorial phenomena determined by personal, socio-demographic, and lifestyle- and health-related factors, as well as organisational determinants, healthcare management, and legislation. In most countries with disability pension schemes, permanent WD is usually due to a chronic disease (5) that reduces functional capacity and work ability (1). The key employee-related predictors of WD reported in observational studies can 
be divided into demographic factors (e.g. age, gender, and educational status) (8-10), health status (11), and work (e.g. type of occupation) (12-15). Previous studies also suggest that both short-term (16-19), and long-term (20-22) sickness absences (SA) predict new periods of sick leave and permanent WD.

The term "subjective cognitive complaints" (SCC) refers to difficulties with concentration, memory, decision making, and clear thinking $(23,24)$. Cognitive complaints hamper the mental executive capacity to prioritize competing tasks, switch between tasks, monitor multiple sources of data, and resist distractions from the task. SCC have been associated with objective cognitive function in studies that have employed comprehensive SCC measures (3). SCC are common in the general and working population and often co-occur with other common psychological health problems (23). The prevalence of SCC increases with age (25). In the ageing population, the factors contributing to cognitive decline include disease burden, for example, poor sleep quality and depressive symptoms (26). In the working population, in addition to other functional syndromes, stress-related conditions often entail exhaustion, sleep problems, and depressive symptoms - i.e. factors that reduce WA in phases that are not characterised by clinical illness (27). A recent systematic review found evidence of physical (cardiovascular diseases and their risk factors), psychological (insomnia and depressive symptoms), and occupational consequences (job satisfaction, absenteeism, new disability pensions, and sickness absences) due to stress in the workplace (28). It has also been suggested that SCC as such reduce WA (27), but compelling evidence is scarce.

The present study was undertaken to assess weather SCC predict permanent WD. We evaluated how an SCC questionnaire used in clinical practice to recognize cognitive impairment (29) predicts DB among respondents from various knowledge-intensive, sedentary occupations. We considered the potential confounding effects of gender, age, and prior sickness absence (SA) days 
as a proxy measure of general health. Our underlining hypothesis was that SCC, indicating hampered cognition in demanding tasks, predict DB.

\section{Methods}

\section{Study design, ethics, and setting}

The study design was an analysis of prospectively collected register data. We obtained the questionnaire data and the SA data from one occupational health service (OHS) provider's registers. The DB data were obtained from the Finnish Centre for Pensions (ETK), which combines DBs under different pension act legislation into one file that is linked to the employee's career, not to a particular employer, and the coverage of the register is practically $100 \%$. We then combined the data registers using a unique identifier, the Finnish social security code. Data privacy was strictly followed.

The Tampere University Research Ethics Board approved the study (ETL code R16074), and it was conducted in accordance with the Declaration of Helsinki.

The study setting is preventive OHS in Finland within the context of Finnish DB legislation.

\section{Participants}

The study participants were professional/managerial employees aged 18-68 who had completed the questionnaire $(\mathrm{N}=13,125)$ during $2010-2016$ as a part of nationwide OHS service provision at one service provider. The information on the archival data of DB from the ETK covered the years 2009-2017. We had access to the complete information on all DB events including the participants' primary and secondary diagnoses based on the International Classification of Diseases, 10th Revision. The study flow with the participants' inclusion and exclusion criteria are displayed in Figure 1. 
The questionnaire was completed as a part of an occupational health surveillance programme. Usually, occupational surveillance is conducted every three years, and some of the employees had participated in multiple rounds of surveillance during the eight-year follow-up. The exclusion criteria were an unknown identification code $(\mathrm{N}=3343)$, other than first response $(\mathrm{N}=2,117)$, occupational group other than professional/manager $(\mathrm{N}=462)$, and previously granted permanent $\mathrm{DB}(\mathrm{N}=98)$.

The final sample size was $N=7,161$. The exact response rate is not available, because the exact number of invitations was not available in the registry data. In a previous cohort study with the same instrument, the response rate was $64 \%$ (30).

\section{Questionnaire}

The online questionnaire is used in Finland as a part of preventive OHS by one nationwide provider to recognize employees at risk of exhaustion and to target interventions for those in need. The questionnaire includes a set of nine screening questions derived from various theoretical frameworks to assess psychosocial workload and individual resources for coping. If any of the trigger questions indicates potential psychosocial problems at work, seven additional questions concerning cognitive function are asked. Table 1 shows the topics and cut-off limits of the trigger questions. 
Table 1. Topics and cut-off limits for the trigger questions.

\begin{tabular}{|c|c|}
\hline Topic & Cut-off limits* \\
\hline 1. Duration of working hours per week. & $\geq 45$ hours/week. \\
\hline $\begin{array}{l}\text { 2. Time pressure from workload and feeling of } \\
\text { strain within the last two months. }\end{array}$ & Continuous perception of pressure and job strain. \\
\hline $\begin{array}{l}\text { 3. Ability to achieve meaningful outcomes at work, } \\
\text { which gives satisfaction. }\end{array}$ & Completely disagree. \\
\hline 4. Self-perception of overall resources. & $\begin{array}{l}\text { With the current working tempo, individual resources } \\
\text { remain adequate at the maximum for another } 6 \\
\text { months. }\end{array}$ \\
\hline 5. Well-being and energy. & $\begin{array}{l}\text { The last time when felt well and energized was already } \\
\text { over } 3 \text { months ago. }\end{array}$ \\
\hline 6. Physical condition. & Poor. \\
\hline 7. Psychological resources. & Feeling overloaded, but able to cope. \\
\hline 8. Level of energy after a working day. & $\begin{array}{l}\text { Three or less on a scale from 1-10 (1=extremely tired, } \\
10=\text { extremely energetic). }\end{array}$ \\
\hline 9. Sleep difficulties within the last three months. & At least three nights per week. \\
\hline
\end{tabular}

* If any of the trigger questions met or exceeded the cut-off, the additional seven questions concerning subjective cognitive complaints (SCC) were asked.

Table 2 shows the topics for the seven questions that are used to calculate the SCC score. The response options for the SCC categories are 1) I strongly disagree, 2) I somewhat disagree, 3) I somewhat agree, and 4) I strongly agree with the question. The SCC score is calculated as the average of the seven questions. The cut-off limit for the abnormal SCC score, $\geq 2.4$, is based on a preliminary non-published study $(\mathrm{N}=30)$ where participants responded to the SCC questions and conducted neuropsychological examinations. Cronbach's alpha for the SCC score in our data was 0.98 . 
Table 2. The topics for the questions that formed subjective cognitive complaints (SCC) score.

1. Memory difficulties

2. Difficulties in planning and organizing own work tasks

3. Forgetting agreed issues and work tasks

4. Difficulties in concentration

5. Delays in recollection

6. Disruptions to thinking

7. Difficulties in recollection

\section{Variables}

\section{Outcome measure}

The outcome variable was a granted $\mathrm{DB}$ as a proxy measure of permanent WD, and it was operationalized dichotomously as a granted DB: yes/no. The mean follow-up time was 3.0 years (SD 1.8, range from 44 days to 7.2 years, median 2.9 years) from the date of the survey response.

DBs in our study consist of four categories as follows: 1) full and 2) partial disability pension, or 3) full and 4) partial rehabilitation subsidy. A DB is granted if the remaining maximum capacity to work is $40 \%(2 / 5)$, as in the case of a full-time benefit; or $60 \%(3 / 5)$, as in the case of a partial benefit. The duration of the DB can be until further notice or for a temporary period. The common requirement in all categories of DB is the permanent nature of the reduction of work ability.

\section{Exposure variable}

We classified the results concerning SCC as follows. First, the respondents who did not indicate any problems with the psychosocial screening questions, and therefore were not asked the SCC questions, were classified as belonging to the reference class. Second, we categorized the SCC score into normal/abnormal, based on the a priori cut-off limit. Thus, the exposure variable consists of 
three categories: 1) reference (no psychosocial load); 2) some psychosocial load, but normal SCC score; and 3) psychosocial load and abnormal SCC score.

\section{Potential confounding factors}

We identified potential confounders in the study as gender (31,32), age (33), general health $(34,35)$, and socioeconomic status (36). We stratified the analyses by gender and included age (four categories) as a potential confounder. Of the available options, we chose to include accumulated SA days before the questionnaire (continuous variable) as a generic measure of health and well-being. Socioeconomic status was operationalized as occupational group and this potential confounder was controlled by the selection of the respondents, who were employees with professional/managerial status only. Other occupational groups (blue-collar workers and clerical employees) were excluded from the study due to small numbers.

\section{Statistical methods}

Baseline characteristics are presented using descriptive statistics. We compared the demographic characteristics of the participants and non-participants by using the t-test and Chi-squared test.

It has been suggested that gender should not be treated as a covariate and that the analyses should be carried out separately by gender (31). Indeed, there were complex and statistically significant interactions in our study between gender and occupational group (data not shown), and we performed all analyses stratified by gender.

We plotted the cumulative incidence function (CIF) to illustrate the difference in DBs between the normal and abnormal SCC score (37). We used the Fine-Gray proportional hazards model to estimate how the SCC categories, age, and prior SA affect the probability of events - i.e. a granted DB - prior to a follow-up (38). The Fine-Gray model gives hazard ratio (HR) estimates to describe the relative effect of covariates, which are then associated with the probability of a DB occurring over 
time. Model 1 is the unadjusted (crude) model and includes only SCC categories (reference/normal/abnormal), and Model 2 is the adjusted model for age and earlier SA days. The estimation of the model parameters was performed using R library cmprsk, with R 3.4.4 software version.

\section{Results}

The average age of the participants was 46.8 (SD 9.8; range 19.2-67.7). Of them, $45 \%(N=, 3255)$ were female. The respondents worked mainly in information and communication technology (48\%, of which $62 \%$ were males); professional, scientific, and technical activities ( $23 \%$, of which $60 \%$ were males); and public administration, defence, and compulsory social security ( $9 \%$, of which $29 \%$ were males). The corresponding figures in Finland are 4\%, 11\%, and 7\% according to Statistics Finland (39). The excluded respondents were slightly older than average (51.6 years, SD 8.98; t 12.3, $p<0.005)$ and a larger proportion of them were men $(67.2 \%$; Chi-squared 102.0, $p<0.005)$ compared to the participants.

A total of 85 participants in the cohort were granted a DB an average of three years after filling out the questionnaire (range from 44 days to 7.2 years). The overall annual DB incidence was $0.15 \%$ : $0.18 \%$ among the females and $0.12 \%$ among the males $(p=0.795)$. In the Fine-Gray model, which included gender as the exposure variable and age and SA days before the questionnaire, the HR for gender was 1.26 (0.81-1.94; males as the reference).

Table 3 shows the causes of DB. Of the participants who received a DB, 31 (37\%) had primary diagnoses of a mental disorder and 17 participants (20\%) had primary diagnoses of a musculoskeletal disorder. Four participants had both musculoskeletal and mental or behavioural diagnoses simultaneously (5\%). 
Table 3: Distribution of causes of disability benefits according to the ICD-10 classification (International Classification of Diseases, $10^{\text {th }}$ Revision). A pension application may include multiple diagnoses, i.e. several ICD-10 classes.

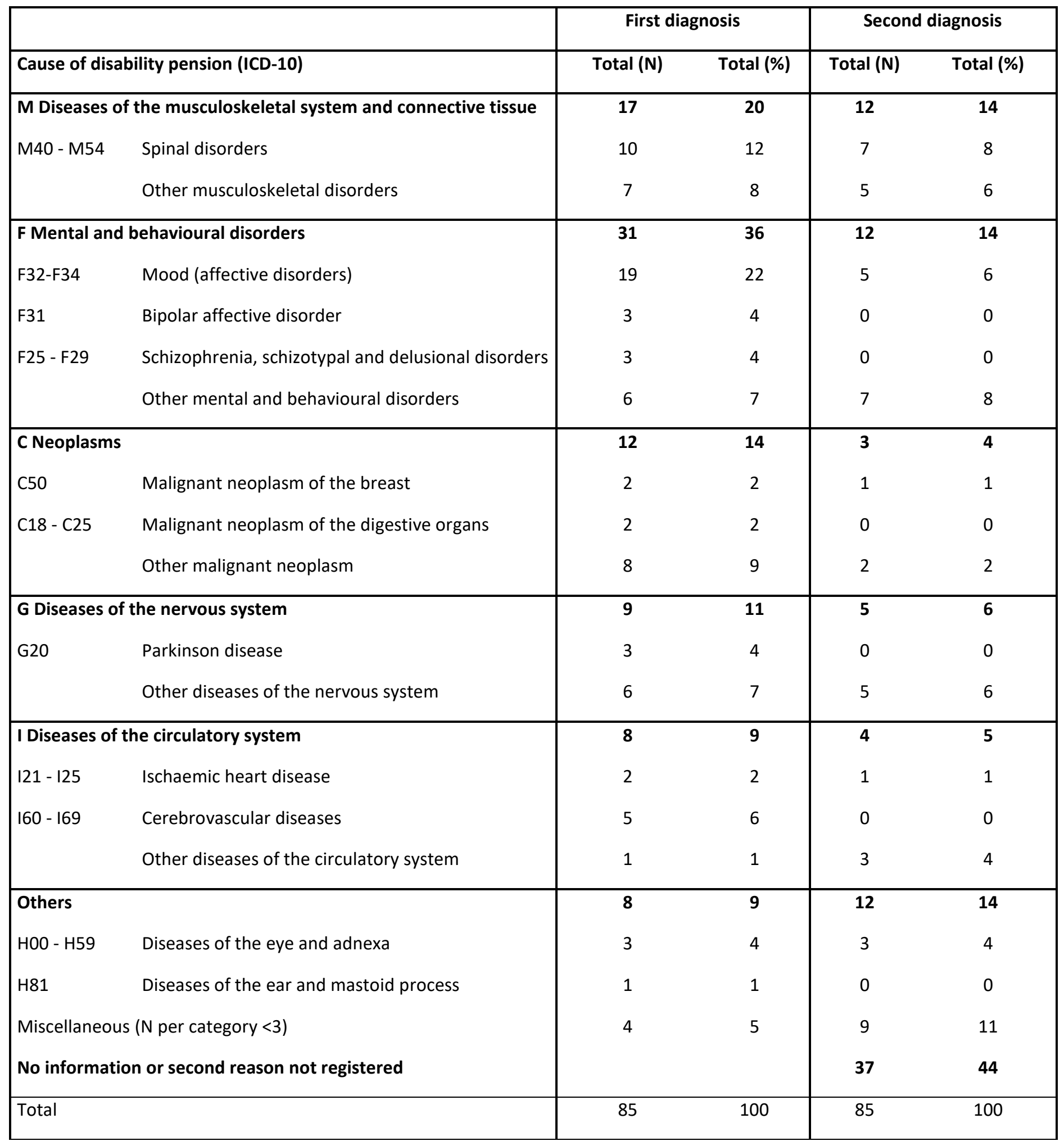


Figure 2 presents the cumulative incidence of DB. Of the females in the abnormal SCC category, 3.1\% had received a DB during the follow-up of eight years, while the respective figure among the males was $2.8 \%$. The respective figures for those in the normal SCC category were $1.9 \%$ for the females and $1.0 \%$ for the males.

Table 4 shows the predictors of DB. In the Fine-Gray model, the unadjusted (Model 1) HR for DB in the abnormal SCC category was 3.3 (1.7-6.6) for the females and 4.1 (1.9-8.5) for the males. In the fully adjusted model (Model 2), the HRs decreased among both genders, being 2.9 (1.4-6.0) for the females and 3.7 (1.8-7.9) for the males. In the fully adjusted model, the HR for SA days before the questionnaire was $1.013(1.010-1.017)$ for the females and $1.018(1.014-1.021)$ for the males. In the fully adjusted model, the HR for DB by age was the highest in the 50-60-year age group for females, at $3.6(1.2-10.5)$.

Table 4: Probability of disability benefit by covariates over time. Subdistribution hazard ratios obtained from the Fine-Gray model describe the relative effect of covariates on the subdistribution hazard function. The covariates in this model can also be interpreted as having an effect on the cumulative incidence function or on the probability of events occurring over time. Model 1 includes the questionnaire subjective cognitive complaints (SCC) score only; Model 2 includes SCC, age, and prior sick leave as a covariate.

\begin{tabular}{|c|c|c|c|c|c|c|}
\hline & \multicolumn{3}{|c|}{ Female } & \multicolumn{3}{|c|}{ Male } \\
\hline Explanatory variable & $\mathbf{N}$ & HR & $95 \% \mathrm{Cl}$ & $\mathbf{N}$ & HR & $95 \% \mathrm{Cl}$ \\
\hline \multicolumn{7}{|l|}{ Model 1 (unadjusted) } \\
\hline SCC: questions did not open & 1,415 & 1.0 & ref. & 2,021 & 1.0 & ref. \\
\hline SCC: normal & 1,225 & 1.2 & {$[0.6-2.6]$} & 1,372 & 1.4 & {$[0.6-3.0]$} \\
\hline SCC: abnormal & 615 & 3.3 & {$[1.7-6.6]$} & 513 & 4.1 & [1.9-8.5] \\
\hline \multicolumn{7}{|l|}{ Model 2 (adjusted) } \\
\hline SCC: questions did not open & 1,415 & 1.0 & ref. & 2,021 & 1.0 & ref. \\
\hline SCC: normal & 1,225 & 1.2 & {$[0.5-2.7]$} & 1,372 & 1.3 & {$[0.6-3.0]$} \\
\hline SCC: abnormal & 615 & 2.9 & {$[1.4-6.0]$} & 513 & 3.7 & [1.8-7.9] \\
\hline Age $<40$ & 834 & 1.0 & ref. & 1,187 & 1.0 & ref. \\
\hline Age $\geq 40$ and $<50$ & 952 & 2.8 & {$[0.9-8.3]$} & 1,142 & 0.8 & {$[0.3-2.1]$} \\
\hline Age $\geq 50$ and $<60$ & 1,225 & 3.6 & {$[1.2-10.5]$} & 1,258 & 1.9 & {$[0.8-4.6]$} \\
\hline Age $\geq 60$ & 244 & 1.8 & [0.3-9.7] & 319 & 1.4 & {$[0.4-5.5]$} \\
\hline Sick leave days before the questionnaire & & 1.013 & {$[1.010-1.017]$} & & 1.018 & [1.014-1.021] \\
\hline
\end{tabular}




\section{Discussion}

\section{Key results}

Subjective cognitive complaints (SCC) - self-rated problems in concentration, memory, clear thinking, and decision making - predicted permanent WD in both genders when adjusted for age and SA days before the questionnaire as a proxy measure of general health. It was noteworthy that the accumulation of DBs among those with SCC seems to accelerate only from the third year of follow-up onwards. Thus, the presence of SCC seems to act as an early indicator in identifying employees who are at increased risk for work disability in knowledge-intensive occupations.

\section{Strengths and limitations of the study}

A key strength of our study is its register-based, prospectively analysed data from different industries. We were able to control the key potential confounders, namely age and gender. The quality of the archival DB data from the Finnish Centre for Pensions is good in terms of coverage, accuracy, and consistency over time, and no data are lost to follow-up $(40,41)$.

The follow-up period continued for at least fifteen months after the questionnaire had been completed. Sickness allowance is paid for a maximum of one year after the onset of WD, and the DB decision is typically made immediately after the sickness allowance period. Thus, the follow-up period of fifteen months was long enough to detect all new potential DB recipients.

We chose to use the Fine-Gray model to estimate the effect of the covariates on the rate at which WD occurs. Although the model was perhaps not able to deal with all the complexity associated with our data, among computationally feasible approaches it is more appropriate than Kaplan-Meier survival analysis, for example, as the latter tends to overestimate the cumulative incidence of health-related events (42). Besides, it was easier to add variables to the Fine-Gray model than to Kaplan-Meier. Moreover, we prefer talking about cumulative hazards over "survival 
at work" conceptually. However, interpretation of the HR estimates from the Fine-Gray model is not straightforward. We recommend interpreting the covariates as having an effect on the incidence of WD (i.e. on the CIF). Nevertheless, the magnitude of the relative effect of the covariate on the subdistribution hazard function is different from the magnitude of the effect of the covariate on the CIF. One can still conclude that if a variable increases the subdistribution hazard function, it will also increase the incidence of the event. However, one cannot infer that the exact magnitudes of the two effects are the same (43).

A limitation of our study is the SCC questionnaire's lack of proper psychometric validation. It has previously been studied only in a preliminary study using a selected population from one information technology company (29). However, Cronbach's alpha in our study was at an acceptable level for the SCC (0.98). In the present study, we focused on the predictive validity of abnormal SCC on SA.

The study population consisted solely of professionals/managers in knowledge-intensive sedentary occupations. Cautious generalizations can only be made to other professional groups. People from outside working life were not involved in our study. As we did not analyse statutory accident insurance data, we cannot draw conclusions about the reasons for DB due to accidents at work, occupational diseases, or traffic accidents. Another limitation of the study is the potential selection bias due to differences between respondents and non-respondents. The "healthy worker effect" may be present, since the health of employed people is generally better than that of the unemployed population, and employees with a worse health level may have not responded (44). A similar bias would potentially result from a "healthy worker survival effect", which means that employees with problems with health and well-being are likely to drop out of working life (45). Moreover, we did not include those who had already been granted a DB before the questionnaire. 
All this might underestimate the associations. It may also be possible that the healthiest employees did not respond to the questionnaire, which would have an opposite effect on our estimates.

Some DB criteria are comparable between countries and legislation, such as requirements for a health condition in relation to work and the permanence of the condition (5). As the implementation of the legislation varies across countries (1), the results of our study must be interpreted with caution in the international context. However, we assume that the phenomenon itself - that subjective cognitive complaints predict WD - manifests in different medico-legal contexts.

\section{Similarities and differences to previous studies}

An earlier preliminary cohort study $(\mathrm{N}=180)$ shows that within the abnormal SCC category group, $42 \%$ of professional/managerial employees had a long-term SA (over 30 days) (29). Another cohort study $(\mathrm{N}=2,898)$ found that the abnormal SCC category had an association with an increasing number of SA days (13.9 SA days/employee/year) when compared to those with a normal SCC category (5.3 SA days/employee/year) (30). Our study is line with these earlier studies, although we operationalized permanent WD as DB.

To the best of our knowledge, there are no previous studies concerning the relationship between SCC and permanent WD. Previous studies that have analysed the relationships between SCC and permanent WD have focused either on a particular illness (46) or general ageing (25). Most studies focus on the health-related conditions that are linked to SCC, such as depression (47) or stress-related symptoms (burnout/exhaustion) (28). Obviously, these conditions are related to permanent WD $(48,49)$.

By age, the risk of DB was the highest in the 50- to 60-year age group in our study population, though it was not statistically significant among the males. This might be due to the "healthy worker 
survivor effect", which means that those who become unwell or unfit during their employment tend to leave working life earlier (33).

We performed the analyses separately for males and females due to interactions between gender and other covariates (data not shown), as suggested earlier (32). A previous SCC study also found significant gender interaction (23).

Our results are in line with earlier findings that the accumulation of SA predicts DB $(16,50)$, and that the main causes of DB in Finland are diseases of the musculoskeletal system and mental disorders (48,51-56).

The annual incidence of DB was only $0.15 \%$ in the entire cohort and the three-fold relative risk is small in terms of absolute risk increase. However, since WD is so costly for society (1) and burdensome for the disabled individuals themselves, prevention of permanent WD is important. Moreover, as the working population is ageing, and at the same time working life is becoming increasingly demanding cognitively and psychosocially $(57,58)$, it is important to identify the psychosocial predictors of WD to determine how to prevent ill health and subsequent WD among professional/managerial employees. Further research is needed to understand the causal pathways between psychosocial risks, cognitive impairment, illnesses, work productivity, and WD. Further research is also needed to assess the effectiveness and cost-effectiveness of preventive OHS interventions for employees at risk based on SCC.

\section{Conclusions}

Subjective cognitive complaints predict permanent work disability among knowledge-intensive occupations and therefore seem to act as an indicator of future work disability risk. This finding has implications for supporting work productivity among employees with cognitively demanding tasks.

\section{Abbreviations}

DB

disability benefit 


$\begin{array}{ll}\text { ETK } & \text { Finnish Centre for Pensions } \\ \text { HR } & \text { hazard ratio } \\ \text { Kela } & \text { the Social Insurance Institution of Finland } \\ \text { OHS } & \text { occupational health service } \\ \text { SA } & \text { sickness absence } \\ \text { SD } & \text { standard deviation } \\ \text { SCC } & \text { subjective cognitive complaints } \\ \text { WD } & \text { work disability }\end{array}$

\section{Declarations}

Ethical approval and consent to participate: The Tampere University Research Ethics Board approved the study (ETL code R16074). This study used solely secondary data retrieved from registers.

Consent for publication: On behalf of all authors, the Corresponding Author has the right to grant and does grant an exclusive license (or non-exclusive license for UK Crown and US Federal Government employees) on a worldwide basis to BMC Public Health and its Licensees to permit this article (if accepted) to be published and to exploit all subsidiary rights as set out in our license. The article has not been published previously and it is not under consideration for publication elsewhere.

Availability of data and material: No additional data are available due to data privacy reasons. Competing interest: MP has a Finnish Work Environment Fund scholarship; HAR and HAH are employed by Terveystalo; ST is employed by Evalua International; and JU, JO, MK, and TN are employed by the University of Tampere. There are no other competing interests to declare. Funding: This work was supported by Terveystalo (HAR and HAH), Evalua International (ST), and the University of Tampere (JU, JO, MK and TN) as the role of the employer. 
Authors contributions: MP, JU, HA, JO, and ST participated in planning the study. MK and TN

conducted the statistical analyses. MP, HAR, HAH, and ST interpreted the results. MP and ST wrote the first draft of the manuscript and all authors commented on and approved the final manuscript as submitted.

Acknowledgements: Not Applicable.

\section{References}

(1) OECD (Organisation for Economic Co-operation and Development). Sickness, Disability and Work: Breaking the Barriers: A Synthesis of Findings across OECD Countries. OECD Publishing 2010. Published also on internet. Accessed November, 2019. Available from: doi://dx.doi.org/10.1787/9789264088856-en.

(2) Rechel B, Grundy E, Robine JM, Cylus J, Mackenbach J, Knai C, et al. Ageing in the European Union. Lancet, The 2013;381(9874):1312-1322.

(3) OECD (Organisation for Economic Co-operation and Development). Pensions at a Glance, 2017: OECD and G20 Indicators. OECD Publishing 2018, Paris. Published also on internet. Accessed October, 2019. Available from: https://www.oecd.org/pensions/oecd-pensions-at-a-glance-19991363.htm

(4) Korunka C, Kubicek B. Job Demands in a Changing World of Work. InJob demands in a changing world of work 2017 (pp. 1-5). Springer, Cham.

(5) De Boer, W. E. L., Donceel P, Brage S, Rus M, Willems, J. H. B. M. Medico-legal reasoning in disability assessment: a focus group and validation study. BMC Public Health 2008;8(1):335.

(6) Official Statistics, Finland. Recipients of disability pension. 2018. Published on internet, last updated April, 2019 Accessed October, 2019. Available from: https://findikaattori.fi/en/76

(7) Finnish Centre for Pensions, Official Statistics of Finland. Suomen työeläkkeensaajat 2017, Arbetspensionstagare i Finland 2017, Earnings-related pension recipients in Finland 2017 . Tampere: Juvenes Print - Suomen Yliopistopaino Oy; 2018. Published also on internet. Accessed September, 2019. Available from: https://www.etk.fi/wp-content/uploads/suomen-tyoelakkeensaajat2017.pdf

(8) Samuelsson Å, Alexanderson K, Ropponen A, Lichtenstein P, Svedberg P. Incidence of disability pension and associations with socio-demographic factors in a Swedish twin cohort. Soc Psychiatry Psychiatr Epidemiol 2012;47(12):1999-2009.

(9) Polvinen A, Laaksonen M, Gould R, Lahelma E, Leinonen T, Martikainen P. Socioeconomic Differences in Cause-Specific Disability Retirement in Finland, 1988 to 2009. J Occup Environ Med 2016;58(8):840-845.

(10) Laaksonen M, Blomgren J, Gould R. Sickness allowance trajectories preceding disability retirement: A register-based retrospective study. Eur J Public Health 2016;26(6):1050-1055. 
(11) Karpansalo M, Manninen P, Kauhanen J, Lakka TA, Salonen JT. Perceived health as a predictor of early retirement. Scand J Work Environ Health 2004:287-292.

(12) Haukenes I, Mykletun A, Knudsen AK, Hansen H, Mæland JG. Disability pension by occupational class the impact of work-related factors: The Hordaland Health Study Cohort. BMC public health 2011 May $30, ; 11(1): 406$.

(13) Leinonen T, Pietiläinen O, Laaksonen M, Rahkonen O, Lahelma E, Martikainen P. Occupational social class and disability retirement among municipal employees - the contribution of health behaviors and working conditions. Scand J Work Environ Health 2011;37(6):464-472.

(14) Polvinen A, Laaksonen M, Gould R, Lahelma E, Martikainen P. The contribution of major diagnostic causes to socioeconomic differences in disability retirement. Scand J Work Environ Health 2014;40(4):353360.

(15) K B, G H, K A, Linköpings universitet, Institutionen för hälsa och samhälle, Hälsouniversitetet. Predictive factors for disability pension - An 11-year follow up of young persons on sick leave due to neck, shoulder, or back diagnoses. Scand J Public Health 2001;29(2):104-112.

(16) Kivimäki M, Forma P, Wikström J, Halmeenmäki T, Pentti J, Elovainio M, et al. Sickness Absence as a Risk Marker of Future Disability Pension: The 10-Town Study. J Epidemiol Community Health (1979-) 2004;58(8):710-711.

(17) Virtanen M, Kivimäki M, Vahtera J, Elovainio M, Sund R, Virtanen P, et al. Sickness Absence as a Risk Factor for Job Termination, Unemployment, and Disability Pension among Temporary and Permanent Employees. Occup Environ Med 2006;63(3):212-217.

(18) Alexanderson K, Kivimäki M, Ferrie JE, Westerlund H, Vahtera J, Singh-Manoux A, et al. Diagnosisspecific sick leave as a long-term predictor of disability pension: a 13-year follow-up of the GAZEL cohort study. J Epidemiol Community Health 2012;66(2):155-159.

(19) Karlsson NE, Carstensen JM, Gjesdal S, Alexanderson KAE, Institutionen för medicin och hälsa, Linköpings universitet, et al. Risk factors for disability pension in a population-based cohort of men and women on long-term sick leave in Sweden. Eur J Public Health 2008;18(3):224-231.

(20) Gjesdal S, Ringdal PR, Haug K, Mæland JG. Predictors of disability pension in long-term sickness absence: Results from a population-based and prospective study in Norway 1994-1999. Eur J Public Health 2004;14(4):398-405.

(21) Lund T, Kivimäki M, Labriola M, Villadsen E, Christensen KB. Using administrative sickness absence data as a marker of future disability pension: the prospective DREAM study of Danish private sector employees. Occup Environ Med 2008;65(1):28-31.

(22) Airaksinen J, Jokela M, Virtanen M, Oksanen T, Koskenvuo M, Pentti J, et al. Prediction of long-term absence due to sickness in employees: Development and validation of a multifactorial risk score in two cohort studies. Scand J Work Environ Health 2018;44(3):274-282.

(23) Stenfors CUD, Hanson Magnusson L, Oxenstierna G, Theorell T, Nilsson L. Psychosocial Working Conditions and Cognitive Complaints among Swedish Employees. PLoS ONE 2013;8(4):e60637. 
(24) Stenfors CUD, Marklund P, Hanson LLM, Theorell T, Nilsson L. Subjective Cognitive Complaints and the Role of Executive Cognitive Functioning in the Working Population: A Case-Control Study. PLoS One 2013 Dec 1,;8(12):e83351.

(25) Burmester B, Leathem J, Merrick P. Subjective Cognitive Complaints and Objective Cognitive Function in Aging: A Systematic Review and Meta-Analysis of Recent Cross-Sectional Findings. Neuropsychol Rev 2016;26(4):376-393.

(26) LaMonica HM, Hickie IB, Ip J, Ireland C, Mowszowski L, English A, et al. Disability in older adults across the continuum of cognitive decline: Unique contributions of depression, sleep disturbance, cognitive deficits and medical burden. International Psychogeriatrics 2019:1-15.

(27) Aasvik JK, Woodhouse A, Jacobsen HB, Borchgrevink PC, Stiles TC, Landrø NI. Subjective memory complaints among patients on sick leave are associated with symptoms of fatigue and anxiety. Frontiers in Psychology 2015;6:1338.

(28) Salvagioni DAJ, Melanda FN, Mesas AE, González AD, Gabani FL, de Andrade SM. Physical, psychological and occupational consequences of job burnout: A systematic review of prospective studies. PLoS One 2017 Oct 1,;12(10):e0185781.

(29) Ahveninen H, Rintala J, Ollikainen J, Suhonen J, Arola Heikki. TyöOptimi-kysely auttaa tunnistamaan työssäkäyvän kognitiivisia ja muistioireita. Suomen Lääkärilehti 2014;69(4):207-214. Originally published in Finnish, English summary. [WorkOptimum questionnaire helps to detect memory and cognitive symptoms among working people. Finnish Medical Journal 2014;69(4):207-14].

(30) Ahveninen H, Arola H, Ollikainen J. Kysely tunnistaa sairauspoissaoloriskin tietotyössä. Suomen Lääkärilehti 2019 May 10;19(74):1198-1207. Originally published in Finnish, English summary. [Can knowledge-intensive workers at risk of absenteeism be identified using a questionnaire? Finnish Medical Journal 2019;19(74):1198-207].

(31) Messing K, Punnett L, Bond M, Alexanderson K, Pyle J, Zahm S, et al. Be the fairest of them all: challenges and recommendations for the treatment of gender in occupational health research. Am $\mathrm{j}$ industrial medi 2003;43(6):618.

(32) Messing K, Mager Stellman J. Sex, gender and women's occupational health: The importance of considering mechanism. Environmental Research 2006;101(2):149-162.

(33) Osmotherly P, Attia J. The healthy worker survivor effect in a study of neck muscle performance measures in call-centre operators. Work 2006;26(4):399-406.

(34) Ferrie JE, Vahtera J, Kivimäki M, Westerlund H, Melchior M, Alexanderson K, et al. Diagnosis-specific sickness absence and all-cause mortality in the GAZEL study. J Epidemiol Community Health (1979-) 2009;63(1):50-55.

(35) Kivimäki M, Head J, Ferrie JE, Shipley MJ, Vahtera J, Marmot MG. Sickness absence as a global measure of health: evidence from mortality in the Whitehall II prospective cohort study. BMJ 2003;327(7411):364.

(36) Bouville G, Dello Russo S, Truxillo D. The moderating role of age in the job characteristics-absenteeism relationship: A matter of occupational context? J Occup Organ Psychol 2018;91(1):57-83. 
(37) Kim HT. Cumulative Incidence in Competing Risks Data and Competing Risks Regression Analysis. Clinical Cancer Research 2007;13(2):559-565.

(38) Fine JP, Gray RJ. A Proportional Hazards Model for the Subdistribution of a Competing Risk. Journal of the American Statistical Association 1999;94(446):496-509.

(39) Findicator. Statistics Finland. Employed persons by industry. Published on internet 11 April 2019. Accessed October 2019. Available from: https://suhdannepalvelu.stat.fi/en/12.

(40) Kela K, Folkpensionsanstalten F. Kelan tilastollinen vuosikirja 2016. [Statistical Yearbook of the Social Insurance Institution 2016].Published on internet November 2017. Accessed October, 2018. Available from: https://helda.helsinki.fi/bitstream/handle/10138/228883/Kelan_tilastollinen_vuosikirja_2016.pdf

(41) Finnish Centre for Pensions - Producer of Statistics. 2018; . Accessed October, 2018. Published on internet December, 2018. Available from: https://www.etk.fi/en/statistics-2/statistics/producer-ofstatistics/

(42) Lacny S, Wilson T, Clement F, Roberts DJ, Faris P, Ghali WA, et al. Kaplan-Meier survival analysis overestimates cumulative incidence of health-related events in competing risk settings: a meta-analysis. J Clinical Epidemiology 2018 Jan;93:25-35.

(43) Austin PC, Fine JP. Practical recommendations for reporting Fine-Gray model analyses for competing risk data. Statistics in Medicine 2017 Nov 30,;36(27):4391-4400.

(44) Chowdhury R, Shah D, Payal AR. Healthy worker effect phenomenon: Revisited with emphasis on statistical methods-A review. Indian journal of occupational and environmental medicine 2017;21(1):2.

(45) Nordström K, Hemmingsson T, Ekberg K, Johansson G. Sickness absence in workplaces. Int J Occup Med Environ Health 2016;29(2):315.

(46) Cognitive function predicts work disability among multiple sclerosis patients. Multiple Sclerosis Journal-Experimental, Translational and Clinical. 2019 Jan;5(1):2055217318822134.

(47) Amiri S, Behnezhad S. Depression and risk of disability pension: A systematic review and meta-analysis. The International Journal of Psychiatry in Medicine 2019 May 6,:9121741983741-91217419837412.

(48) Juvani A, Oksanen T, Virtanen M, Elovainio M, Salo P, Pentti J, et al. Organizational justice and disability pension from all-causes, depression and musculoskeletal diseases: A Finnish cohort study of public sector employees. Scand J Work Environ Health 2016;42(5).

(49) Ervasti J, Mattila-Holappa P, Joensuu M, Pentti J, Lallukka T, Kivimäki M, et al. Predictors of Depression and Musculoskeletal Disorder Related Work Disability Among Young, Middle-Aged, and Aging Employees. J occup environ med 2017 Jan;59(1):114-119.

(50) Salonen L, Blomgren J, Laaksonen M, Niemelä M. Sickness absence as a predictor of disability retirement in different occupational classes: a register-based study of a working-age cohort in Finland in 2007-2014. BMJ Open 2018;8(5):e020491.

(51) Olesen SC, Butterworth P, Rodgers B. Is poor mental health a risk factor for retirement? Findings from a longitudinal population survey. Soc Psychiatry Psychiatr Epidemiol 2012;47(5):735-744. 
(52) Dorner TE, Alexanderson K, Svedberg P, Ropponen A, Stein KV, Mittendorfer-Rutz E. Sickness absence due to back pain or depressive episode and the risk of all-cause and diagnosis-specific disability pension: A Swedish cohort study of 4,823,069 individuals. European Journal of Pain 2015;19(9):1308-1320.

(53) Mäntyniemi A, Oksanen T, Salo P, Virtanen M, Sjösten N, Pentti J, et al. Job strain and the risk of disability pension due to musculoskeletal disorders, depression or coronary heart disease: a prospective cohort study of 69842 employees. Occup Environ Med 2012;69(8):574-581.

(54) Ahola K, Virtanen M, Honkonen T, Isometsä E, Aromaa A, Lönnqvist J. Common mental disorders and subsequent work disability: a population-based Health 2000 Study. J Affect Disord 2011;134(1-3):365-372.

(55) Kaila-Kangas L, Haukka E, Miranda H, Kivekäs T, Ahola K, Luukkonen R, et al. Common mental and musculoskeletal disorders as predictors of disability retirement among Finns. J Affect Disord 2014;165:3844.

(56) Lahelma E, Laaksonen M, Lallukka T, Martikainen P, Pietiläinen O, Saastamoinen $\mathrm{P}$, et al. Working conditions as risk factors for disability retirement: A longitudinal register linkage study. BMC Public Health 2012;12(1):309.

(57) Gijselaers HJM, Meijs C, Neroni J, Kirschner PA, de Groot, Renate H M. Updating and Not Shifting Predicts Learning Performance in Young and Middle-Aged Adults: Executive Functions and Learning Performance. Mind, Brain, and Education 2017;11(4):190-200.

(58) Singh-Manoux A, Kivimaki M, Glymour MM, Elbaz A, Berr C, Ebmeier KP, et al. Timing of onset of cognitive decline: results from Whitehall II prospective cohort study. BMJ 2012;344:d7622.

\section{Figure legends:}

\section{Figure 1: Study flow.}

Figure 2: Cumulative incidence of disability benefits over the eight-year follow-up period by subjective cognitive complaints (SCC) among females and males. Estimates are unadjusted crude values with no other explanatory variables. The reference category includes the employees with no psychosocial load and the employees with some psychosocial load, but a normal SCC score. 
Figures

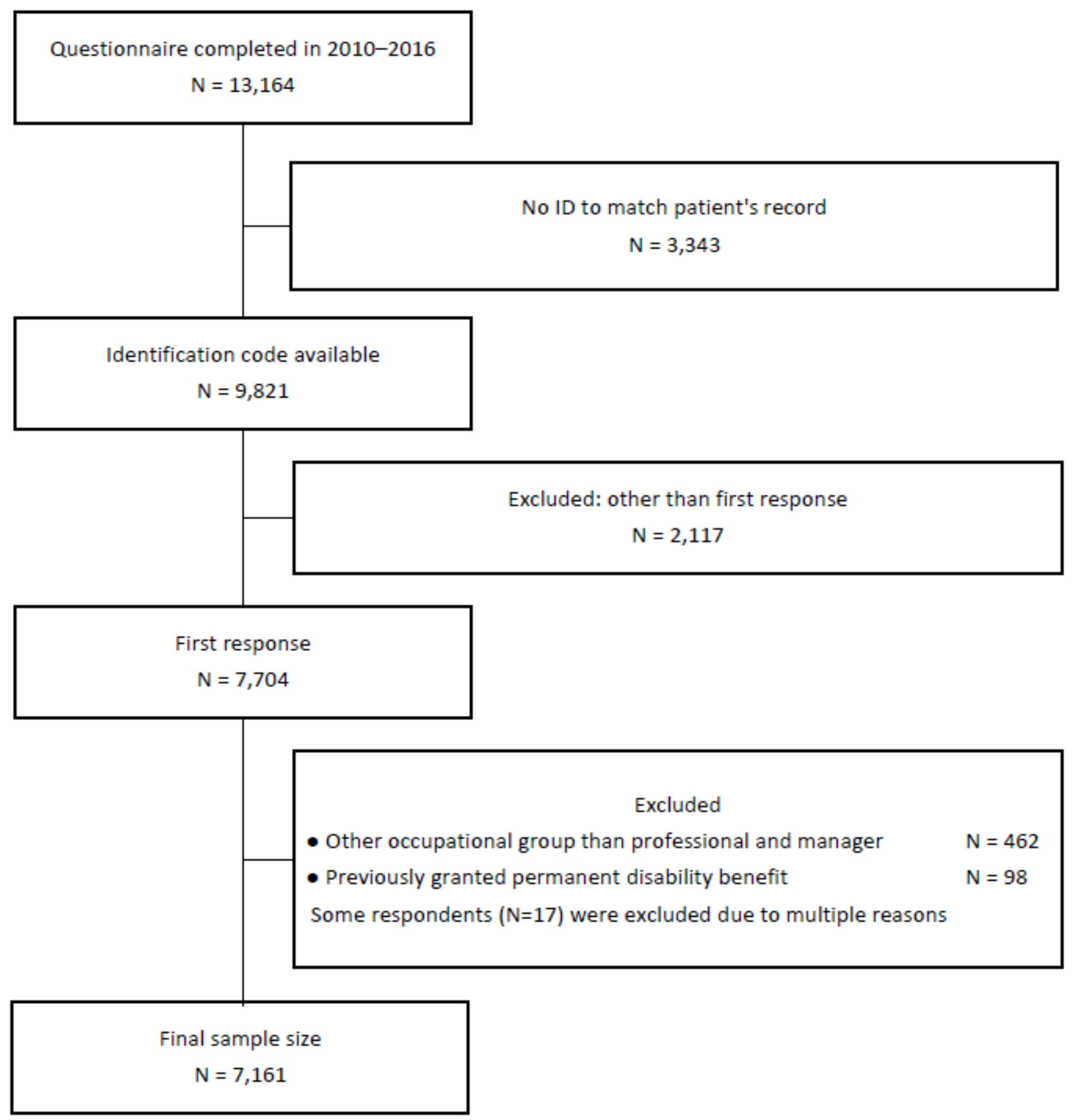

Figure 1

Study flow. 

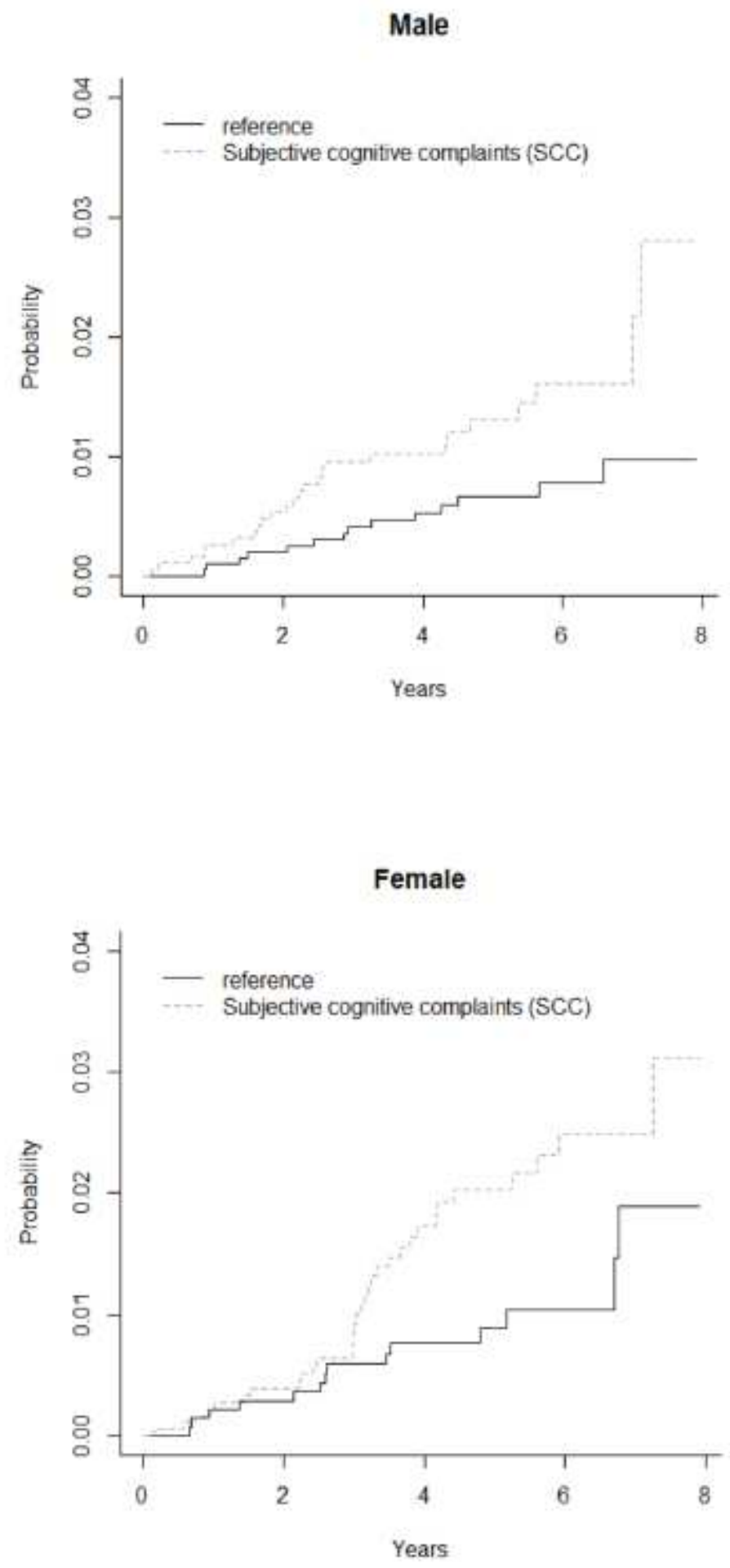

\section{Figure 2}

Cumulative incidence of disability benefits over the eight-year follow-up period by subjective cognitive complaints (SCC) among females and males. Estimates are unadjusted crude values with no other explanatory variables. The reference category includes the employees with no psychosocial load and the employees with some psychosocial load, but a normal SCC score. 